\title{
Cold needle-knife papillotome as rescue dilator for endoscopic ultrasound-guided choledocho- duodenostomy
}

Endoscopic ultrasound (EUS)-guided biliary drainage via either gastrohepatostomy or choledochoduodenostomy are accepted and widespread procedures when endoscopic retrograde cholangiopancreatography (ERCP) fails. EUS guidewire insertion through a 19-G needle into a dilated biliary system is usually a straightforward maneuver. The drainage difficulty begins when the enterobiliary tract has to be dilated over the guidewire to allow the passage of the stent [1]. For this purpose, several dilation devices have been described; some of them employ electric current and others take advantage of the small tip of the device. Initial attempts to enlarge the enterobiliary tract with dilation balloons may fail due to a lack of sufficient stiffness in the tip of the balloon catheter or the inability to inflate the balloon in the middle of the tract. Therefore, another more rigid device needs to be employed prior to balloon dilation. In these situations, we have found the use of a cold needle-knife, without exposure of the wire or use of the electric current, to be helpful.

A 45-year-old man presented with jaundice due to carcinoma in the head of the pancreas and liver metastases. ERCP drainage failed because of disease infiltration into the papillary area. EUS-guided choledochoduodenostomy was attempted. After passing a 0.035-inch, straighttip, guidewire (Jagwire, length $450 \mathrm{~cm}$; Boston Scientific, Natick, Massachusetts, USA) into the common bile duct through a $19-G$ needle ( Fig. 1 ), several devices were unable to follow the guidewire from the duodenal bulb to the common bile duct lumen. Therefore, a needle-knife papillotome (RX Needle Knife XL, triple lumen; Boston Scientific) with a 5.5-Fr tip $(1.8 \mathrm{~mm})$, was pushed firmly over the guidewire, traversing the duodenal and bile duct walls. After removing the needle-knife, a 7-Fr, 7-cm long, plastic biliary stent (Advanix; Boston Scientific) was inserted ( Fig.2). The plastic stent was exchanged 5 weeks later for a fully covered self-expanding metal stent, using a duodenoscope and following balloon tract dilation ( $\bullet$ Fig. 3 and $\bullet$ Fig.4).

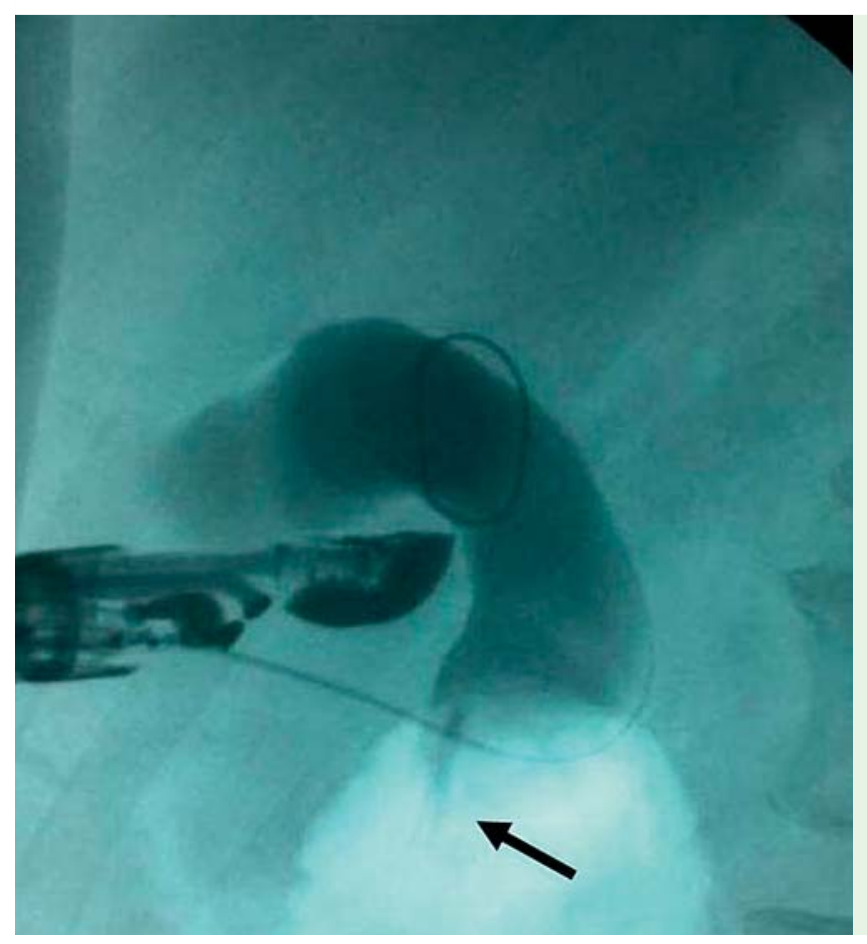

Fig. 1 Endoscopic ultrasound cholangiography. The 19-G needle was removed, leaving a 0.035 -inch guidewire inside the common bile duct. A hemostatic clip (arrow) had been placed previously in the papillary area during the failed endoscopic retrograde cholangiopancreatography.

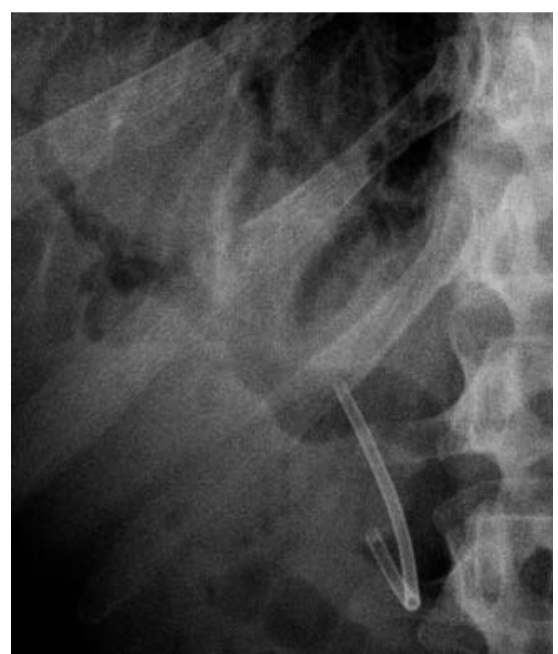

Fig. 2 The tract from the duodenal bulb into the common bile duct was dilated by pushing a needle-knife over the guidewire. After dilation, a 7-Fr plastic stent was placed to create a fistula and to drain the obstructed common bile duct.

Endoscopy_UCTN_Code_TTT_1AS_2AD

Competing interests: None

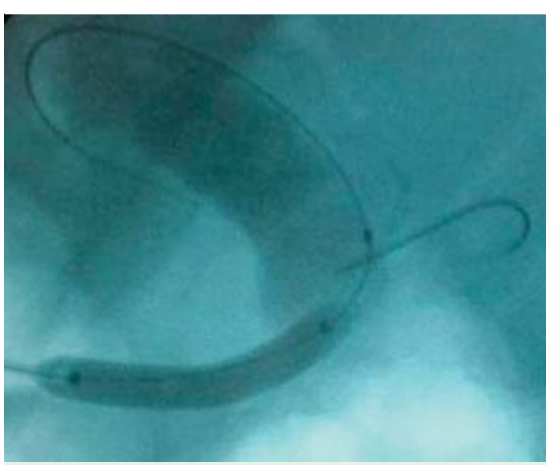

Fig. 3 Several weeks later the enterobiliary tract was dilated using a 6-mm balloon.

\section{Jesús García-Cano}

Department of Digestive Diseases, Hospital Virgen de la Luz, Cuenca, Spain

\section{Reference}

1 Vila JJ, Pérez-Miranda M, Vazquez-Sequeiros $E$ et al. Initial experience with EUS-guided cholangiopancreatography for biliary and pancreatic duct drainage: a Spanish national survey. Gastrointest Endosc 2012; 76: $1133-1141$ 


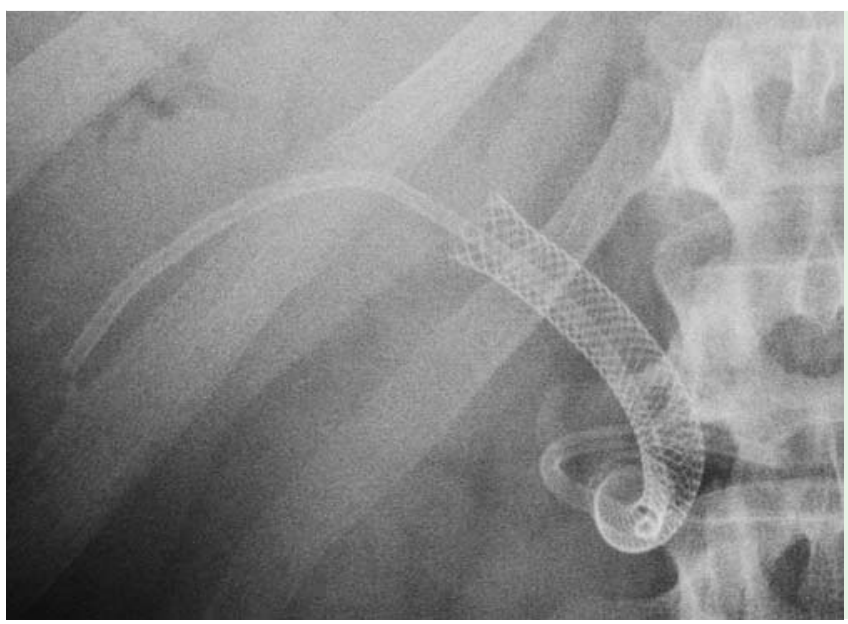

Fig.4 A fully covered self-expanding metal stent (diameter $8 \mathrm{~mm}$, length $8 \mathrm{~cm}$ ) was inserted. A 7-Fr double pigtail plastic stent was also inserted inside the metal stent to prevent dislodgement.

\section{Bibliography}

Dol http://dx.doi.org/

10.1055/s-0034-1377588

Endoscopy 2014; 46: E493-E494

(c) Georg Thieme Verlag KG

Stuttgart · New York

ISSN 0013-726X

\section{Corresponding author}

\section{Jesús García-Cano, MD}

Department of Digestive Diseases Hospital Virgen de la Luz 16002 Cuenca

Spain

Fax: +34-969-230407

jgarciacano@terra.com 